\title{
The occurrence of synanthropic triatomines in Bahia, Brazil: what changed after 40 years of the vector-control program?
}

Gilmar Ribeiro

Centro de Pesquisas Goncalo Moniz https://orcid.org/0000-0003-0980-8762

Cristiane Medeiros Moraes de Carvalho

SESAB

Renato Freitas de Araújo

SESAB

Fernanda Cardoso Lanza

Centro de Pesquisas Goncalo Moniz

Diego Lopes Paim Miranda

IGM/UFBA

Gabriel Muricy Cunha

SESAB

Orlando Marcos Farias de Sousa

Ministry of Health

Carlos G. S. dos Santos

Centro de Pesquisas Goncalo Moniz

Eduardo Oyama Lins Fonseca

Faculdade de Tecnologia SENAI CIMATEC

Roberto Fonseca dos Santos

LACEN-BA

Renato Barbosa Reis

Universidade Salvador

Rodrigo Gurgel-Gonçalves

Universidade de Brasilia

Mitermayer Galvão Reis ( $\square$ miter@bahia.fiocruz.br)

Centro de Pesquisas Goncalo Moniz https://orcid.org/0000-0002-3051-9060

\section{Research}

Keywords: Triatomines, state of Bahia, T. cruzi, Chagas disease, vector-control. 
Posted Date: July 30th, 2020

DOl: https://doi.org/10.21203/rs.3.rs-50744/v1

License: (c) (i) This work is licensed under a Creative Commons Attribution 4.0 International License. Read Full License 


\section{Abstract}

Background: This study presents a descriptive analysis of the occurrence of synanthropic triatomine species in the state of Bahia, before and after the implementation of the vector control program.

Methods: Occurrence and number of collected specimens in the municipalities were analyzed in two periods: (A) 1957 to 1971, before systematic vector control actions; and (B) 2006 to 2019, after the certification of interruption of Chagas disease transmission by Triatoma infestans.

Results: In total, 17 species were recorded during period A and 21 during period B. Panstrongylus megistus was the most frequent species in period A (42\%), while Triatoma pseudomaculata (42\%) and $T$. sordida (38\%) were more frequent in period B. In period A, T. infestans was found in $26(9 \%)$ municipalities, and in period B it was found in 7 (2\%). During period B, most triatomines (88\%) were captured at the peridomestic habitats, with a predominance of $T$. sordida (85\%). Species with greatest relative abundance within the household were T. sordida (49\%), T. brasiliensis (27\%), and $T$. pseudomaculata (15\%).

Conclusions: We have observed a clear reduction in the occurrence of $P$. megistus and T. infestans and an increase in the relative abundance and geographical distribution of T. sordida and T. pseudomaculata after 40 years of the vector-control program. High frequency of other triatomine species in the municipalities of the state of Bahia and a great abundance of $T$. sordida in recent years, highlight the need to reinforce permanent entomological surveillance actions for Chagas disease.

\section{Background}

Triatomines are vectors of the parasite Trypanosoma cruzi, the etiological agent of Chagas disease. Despite being essentially wild insects, some species are capable of adapting to anthropic changes in the natural landscape, occupying the home environment [1, 2]. Many triatomines can invade houses, but few initiate colonization and domiciliation processes, which depends on characteristics of the invasive species [3, 4], of the invaded dwelling [5, 6] and the environment around the household [7].

In Brazil, some triatomine species succeeded in the process of occupying the domestic environment and expanded their occurrence beyond their original biomes [8] by active and passive dispersal $[9,10]$. One of these species was Triatoma infestans, which occupied domiciles in 12 states of Brazil between 1975 and 1983 and it was considered the main species involved in T. cruzi transmission in Brazil $[11,12]$. After control actions were implemented by the National Chagas Disease Control Program since 1975 and by the integrated initiatives of the Southern Cone of Latin America to eliminate T. infestans since 1991, a sustained reduction in domestic populations of vectors was observed [13-15]. In 2006, Brazil received from PAHO/WHO the certification of interruption of Chagas disease transmission by T. infestans [16].

In the state of Bahia, Pirajá da Silva performed the first research with triatomines in 1911, shortly after the T. cruzi description by Carlos Chagas [17]. Pirajá da Silva identified Conorhinus megistus triatomines 
(syn. Panstrongylus megistus) from the city of Mata de São João, next to the city of Salvador, in the state of Bahia. He also identified triatomines in the cities of Feira de Santana, Candeias, São Francisco do Conde, and Salvador [18]. Almost 40 years after Pirajá's initial description, Chagas disease was recognized as a serious health problem in the state of Bahia, where triatomines were captured simultaneously to the record of autochthonous cases of Chagas heart disease in Salvador [19]. Panstrongy/us megistus and Triatoma rubrofasciata were found naturally infected by $T$. cruzi in Salvador's historic center, associated with human cases, which motivated a chemical control campaign [20]. However, there were still foci of $P$. megistus, responsible for $T$. cruzi transmission to families in the neighborhoods of Salvador [21]. In the early 1970s, more than 600 specimens of $P$. megistus and $T$. rubrofasciata were examined in Salvador, among which $16 \%$ were infected by $T$. cruzi [22]. During this period, efforts have been made to identify triatomines in the state of Bahia, and 18 triatomine species were cataloged until the 1970s [23]. After this period, new records have been performed and new species have been described. Currently, 26 triatomine species are recognized in the state of Bahia [24-26]. Epidemiology of Chagas disease demonstrates that the state of Bahia presented higher prevalence ( $0.77 \%$ to $2.22 \%)$ when compared to the Northeast region of the country $(0.69 \%$ to $0.88 \%)$ between 1987 and 1994 [15]. Most recent data (2008 to 2017) indicates that mortality rate from Chagas disease in the state of Bahia (3.8 to 4.8 deaths/100,000 habitants) is the highest among Northeastern states and the fourth highest among all Brazilian states; two deaths occurred in children younger than one year old, indicating the presence of acute cases [26].

Several factors can modify spatial and temporal occurrence of synanthropic triatomine species, particularly vector control through the use of insecticides, housing improvement programs, permanent training actions to combat endemic diseases, and health education for residents of the inspected households [12-16]. Comparative analyses on the dynamics of the spatial and temporal distribution of $T$. cruzi vectors are relevant for epidemiological surveillance of Chagas disease. In the present study we described the occurrence of synanthropic triatomines before (1957 to 1971) and after (2006 to 2019) the implementation of the vector-control program in the state of Bahia, which is the Brazilian state with the greatest diversity of species and the highest mortality rate from this disease in Northeastern Brazil.

\section{Methods}

The state of Bahia has 417 municipalities and it is located in Northeastern Brazil (Fig. 1). Cerrado is the main biome in Western Bahia, where there is average annual precipitation of 300 to $800 \mathrm{~mm}$, while in the semi-arid region, where Caatinga biome predominates, precipitation is less than $300 \mathrm{~mm}$, with long droughts. On the coast, annual precipitation may exceed $1500 \mathrm{~mm}$ and its main biome is the Atlantic Forest (Fig. 1).

Descriptive analysis of the spatial and temporal distribution of synanthropic triatomines species of Bahia was performed in two periods: (A) from 1957 to 1971 and (B) 2006 to 2019. Information regarding period (A) was obtained from data published by Sherlock and Serafim [22] that presented information from the vector surveillance program of Chagas disease in the state of Bahia between 1957 and 1971, which is a 
period before standardized implementation of vector surveillance programs in the country [27]. During this period, triatomine occurrence data was obtained from 206/290 (71\%) municipalities that existed at the time [22]. Information regarding period (B) was obtained from State Government databases (SESABDIVEP-LACEN/BA) from 275/417 (66\%) current municipalities after the certification of interruption of Chagas Disease transmission by T. infestans [28, 29].

Entomological data was obtained in three different ways: (a) Notification of triatomines (surveillance and community participation) performed by the population itself, taking suspicious insects to health agents; (b) Notification attendance (active surveillance) performed by health agents of each city, dependent on (a); and (c) Active search (active surveillance): vectors are searched in all or part of the household units of the locality, regardless of whether or not the population has made any notification. Data from literature was also included through the Google Scholar platform. Triatomine detection and taxonomic identification were carried out as established by Sherlock and Serafim [22], the National Programme for the Control of Chagas disease and the manual of triatomines of Bahia [26]. The database used in the study was organized with entomological surveillance information obtained at the state level. Each row in the spreadsheet represents a registered triatomine with the following information: species, municipality, date, GIS coordinate, the environment of sampling (intradomestic, peridomestic), and data reference. In period $A$, information regarding the environment of sampling was not available [22]. Geographic coordinates of the points of triatomines' occurrence were organized into spreadsheets. In the absence of specific occurrence points, we used coordinates of the city's headquarter, from the Brazilian Institute of Geography and Statistics (IBGE) [30]. Geoprocessing of the information was performed using ArcGis® Software 10.5 [31].

\section{Results}

In this study, information regarding 213,240 triatomines captured in both periods was evaluated, among which 33,543 for period $A$ and 179,697 for period $B$. The highest number of species was recorded in period $B(n=21)$ and four species already described in Bahia were not detected in the analyzed periods (Table 1). Figure 2 shows the distribution of triatomines in the municipalities in periods $A$ and $B$, and the frequencies of the main species. In period A, P. megistus was the most frequent species (42\%) while in period B, T. sordida and T. pseudomaculata were more frequent. In the last few years, T. pseudomaculata presented greater distribution in the state, recorded in 174/417 (42\%) municipalities of Bahia, followed by T. sordida, recorded in 159/417 (38\%) municipalities (Figure 3). Triatoma brasiliensis was the third species with the highest occurrence in the state (22\%) (Fig. 2). There was a clear reduction in the occurrence of $P$. megistus and $T$. infestans, currently with only residual foci. T. infestans was last recorded in 2015 in the municipality of Novo Horizonte (Fig. 3).

Table 1. Species of synanthropic triatomines from the state of Bahia, Brazil, recorded between 1957-1971 and between 2006-2019. 


\begin{tabular}{|c|c|c|}
\hline \multirow[t]{2}{*}{ Species } & \multicolumn{2}{|c|}{ Period } \\
\hline & A (1957-1971) & B (2006-2019) \\
\hline Cavernicola pilosa Barber, 1937 & $*$ & $*$ \\
\hline Panstrongylus lenti Galvão \& Palma, 1968; & * & * \\
\hline Panstrongylus lutzi (Neiva \& Pinto, 1923); & $\mathbf{X}$ & $\mathbf{X}$ \\
\hline Panstrongylus megistus (Burmeister, 1835); & $\mathbf{X}$ & $\mathbf{X}$ \\
\hline Pantrongylus diasi Pinto \& Lent, 1946; & $\mathbf{X}$ & $\mathbf{X}$ \\
\hline Pantrongylus geniculatus (Latreille, 1811); & $\mathbf{X}$ & $\mathbf{X}$ \\
\hline Parabelminus yurupucu Lent \& Wygodzinsky, 1979 & * & * \\
\hline Psammolestes tertius Lent \& Jurberg, 1965; & $\mathbf{X}$ & $\mathbf{X}$ \\
\hline Rhodnius domesticus Neiva \& Pinto, 1923; & * & * \\
\hline Rhodnius nasutus & & $\mathbf{X}$ \\
\hline Rhodnus neglectus Lent, 1954; & $\mathbf{X}$ & $\mathbf{X}$ \\
\hline Triatoma bahiensis Sherlock \& Serafim, 1967; & $\mathbf{X}$ & \\
\hline Triatoma brasiliensis Neiva, 1911 & $\mathbf{X}$ & $\mathbf{X}$ \\
\hline Triatoma costalimai Verano \& Galvão, 1958; & $\mathbf{X}$ & $\mathbf{X}$ \\
\hline Triatoma infestans (Klug, 1834); & $\mathbf{X}$ & $\mathbf{X}$ \\
\hline Triatoma juazeirensis Costa \& Felix, 2007; & & $\mathbf{X}$ \\
\hline Triatoma lenti Sherlock \& Serafim, 1967; & $\mathbf{X}$ & $\mathbf{X}$ \\
\hline Triatoma melanica Costa, Argolo \& Felix, 2006; & & $\mathbf{X}$ \\
\hline Triatoma melanocephala Neiva \& Pinto, 1923; & $\mathbf{X}$ & $\mathbf{X}$ \\
\hline Triatoma pessoai Sherlock \& Serafim, 1967; & $\mathrm{X}^{* *}$ & \\
\hline Triatoma petrocchiae Pinto \& Barreto, 1925; & $\mathbf{X}$ & $\mathbf{X}$ \\
\hline Triatoma pseudomaculata Corrêa \& Espínola, 1964; & & $\mathbf{X}$ \\
\hline Triatoma rubrofasciata (De Geer, 1773); & $\mathbf{X}$ & $\mathbf{X}$ \\
\hline Triatoma sherlocki Papa, Jurberg, Carcavallo, Cerqueira \& Barata, 2002 & & $\mathrm{X}^{* * *}$ \\
\hline Triatoma sordida (Stål, 1859); & $\mathbf{X}$ & $\mathbf{X}$ \\
\hline Triatoma tibiamaculata Pinto, 1926; & $\mathbf{X}$ & $\mathbf{X}$ \\
\hline Triatoma vitticeps (Stål, 1859); & & $\mathbf{X}$ \\
\hline
\end{tabular}

*Species have already been recorded in Bahia in another period; **Species today is considered synonymous with T. lenti; ${ }^{* * *}$ Captured by health agents in a wild environment.

Analyzing the geographical distribution of the main species before and after control actions, there was a reduction in the occurrence of $P$. megistus in the region of Recôncavo Baiano of the state of Bahia, where Atlantic forest areas predominated. Regarding T. infestans, there were also changes; it was no longer detected in some municipalities in the West (e.g. Santa Maria Vitória, Barreiras) and North (e.g. Juazeiro, Curaçá) of the state of Bahia (Fig. 3) and it started being detected in other municipalities in areas of Caatinga (e.g. Itaguaçu da Bahia, Novo Horizonte) and Atlantic forest (e.g. Tremedal and Presidente Tancredo Neves). There was a higher occurrence of $T$. sordida in Western Bahia, where Cerrado biome predominates, in South Central Bahia and some municipalities of the Recôncavo Baiano, Eastern Bahia. However, there was a greater change in the distribution of T. pseudomaculata, which expanded its area of occurrence in the Western municipalities (Cerrado biome) and the Central region (Caatinga biome) of the state of Bahia (Fig. 3). 
When comparing total number of individuals and relative abundance of species in periods $A$ and $B$, we have observed a reduction in the records of $P$. megistus $(A=22,032,62.1 \% ; B=1,842,1.0 \%)$ and $T$. infestans $(A=1,310,3.7 \% ; B=763,0.4 \%)$ and an increase in the records of $T$. sordida $(A=8,314,23.4 \%, B=146,901$, $81.7 \%)$ and T. pseudomaculata $(A=894,2.5 \%, B=16,717,9.3 \%)$. In period $B$, most triatomines $(88 \%)$ were captured in the peridomestic habitats with $T$. sordida being most predominant (85\%); the species with the highest relative abundance within the households were T. sordida (49\%), T. brasiliensis (27\%) and T. pseudomaculata (15\%) (Table 2).

Table 2. Number of synanthropic triatomines collected in the state of Bahia, by species and environment of collection in Brazil, between 2006 and 2019.

\begin{tabular}{llllllllll}
\hline Species & \multicolumn{1}{l}{ Indoors } & \multicolumn{3}{l}{ Peridomestic } & Not informed & Total \\
\cline { 2 - 9 } & $\mathrm{n}$ & $\%$ & $\mathrm{n}$ & $\%$ & $\mathrm{~N}$ & $\%$ & $\mathbf{N}$ & $\%$ \\
\hline Panstrongylus diasi & 6 & 0.04 & 0 & 0.00 & 0 & 0.00 & 6 & 0.00 \\
P. geniculatus & 64 & 0.41 & 43 & 0.03 & 48 & 1.01 & 155 & 0.09 \\
P. lutzi & 186 & 1.18 & 103 & 0.06 & 80 & 1.68 & 369 & 0.21 \\
P. megistus & 292 & 1.86 & 1435 & 0.90 & 115 & 2.41 & 1842 & 1.03 \\
Psammolestes tertius & 0 & 0.00 & 14 & 0.01 & 25 & 0.52 & 39 & 0.02 \\
Rhodnius nasutus & 4 & 0.03 & 0 & 0.00 & 12 & 0.25 & 16 & 0.01 \\
R. neglectus & 22 & 0.14 & 66 & 0.04 & 12 & 0.25 & 100 & 0.06 \\
Triatoma brasiliensis & 4281 & 27.23 & 6639 & 4.17 & 134 & 2.81 & 11054 & 6.15 \\
T. costalimai & 2 & 0.01 & 0 & 0.00 & 0 & 0.00 & 2 & 0.00 \\
T. infestans & 104 & 0.66 & 642 & 0.40 & 17 & 0.36 & 763 & 0.42 \\
T. juazeirensis & 141 & 0.90 & 42 & 0.03 & 42 & 0.88 & 225 & 0.13 \\
T. lenti & 19 & 0.12 & 197 & 0.12 & 10 & 0.21 & 226 & 0.13 \\
T. melanica & 0 & 0.00 & 19 & 0.01 & 0 & 0.00 & 19 & 0.01 \\
T. melanocephala & 32 & 0.20 & 4 & 0.00 & 197 & 4.13 & 233 & 0.13 \\
T. petrocchiae & 1 & 0.01 & 0 & 0.00 & 0 & 0.00 & 1 & 0.00 \\
T. pseudomaculata & 2348 & 14.94 & 13632 & 8.56 & 737 & 15.45 & 16717 & 9.30 \\
T. rubrofasciata & 4 & 0.03 & 0 & 0.00 & 2 & 0.04 & 6 & 0.00 \\
T. sordida & 7755 & 49.34 & 135865 & 85.34 & 3281 & 68.80 & 146901 & 81.75 \\
T. tibiamaculata & 456 & 2.90 & 500 & 0.31 & 29 & 0.61 & 985 & 0.55 \\
T. vitticeps & 2 & 0.01 & 8 & 0.01 & 28 & 0.59 & 38 & 0.02 \\
\hline TOTAL & 15719 & $100 \%$ & 159209 & $100 \%$ & 4769 & $100 \%$ & 179697 & $100 \%$ \\
\hline
\end{tabular}

Source: SESAB. Legend: $\mathrm{N}=$ Absolute number of samples; Mun. = Number of municipalities; $\%=$ percentage per column.

\section{Discussion}

The present study showed that the occurrence of synanthropic triatomines in the state of Bahia has changed after 44 years of systematized control actions were initiated in 1975. P. megistus was the predominant species between 1957 and 1971. After the certification of interruption of Chagas disease transmission by T. infestans in 2006, T. sordida and T. pseudomaculata became the most frequent species in Bahia. 
Bahia was the last Brazilian state to receive PAHO's certification, probably due to specific T. infestans identification errors and appearance of new records of this species in the study area [32]. Nine species biogeographically unlikely to be found within households in Bahia $[25,33]$ were recorded by the surveillance service: Belminus laportei, Eratyrus mucronatus, Microtriatoma trinidadensis, Panstrongylus tupynambai, P. lignarius, Rhodnius prolixus, Triatoma maculata, T. circummaculata, and T. rubrovaria. To reduce taxonomic identification errors, a guide was developed [33] and, more recently, a guidance manual to the surveillance service of triatomines in Bahia, with identification keys, diagnosis, and distribution of vector species [26].

In general, there was a reduction in the occurrence of the main T. cruzi vector species in the $1960 \mathrm{~s}$ and 1970s. In period A, T. infestans were found in $9 \%$ of the municipalities and represented $3.7 \%$ of collected triatomines while $P$. megistus was found in $42 \%$ of the municipalities, with a relative abundance of $62 \%$ of collected triatomines [23]. In period B, T. infestans were only identified in seven municipalities among residual colonies [34,35], representing $0.4 \%$ of collected triatomines. The occurrence of $P$. megistus has greatly reduced in the state of Bahia, especially in the region of Recôncavo Baiano and the metropolitan region of Salvador. Its occurrence has also reduced in other Brazilian states [11, 36-38]. Three hypotheses could explain this reduction in the metropolitan region of Salvador: (a) Chemical control was successfully performed over four decades resulting in the elimination of domestic populations of $P$. megistus; (b) Intense urbanization on these municipalities resulted in deforestation and fragmentation of Atlantic forest areas, which is the natural habitat of the species [23]; (c) Housing improvement, with progressive depletion of adobe houses [39,40], a favorable environment for $P$. megistus colonization. Elimination of $T$. infestans in several municipalities in Western and Central Bahia can be explained by the T. infestans elimination plan, which was intensified in 2004 with actions of household spraying of insecticides, followed by research and capture of triatomines, completed in about 500,000 homes [26]. However, residual colonies of the species were detected in other municipalities $[28,29]$ which requires constant monitoring to definitively eliminate $T$. infestans from the state of Bahia. Thus, we suggest that surveillance and triatomine control activities should be prioritized in these regions.

In addition to the chemical control performed in Bahia since 1975, intensified in 1991, which aimed to eliminate T. infestans [11, 15], other social actions were implemented by the Federal Government such as the growth acceleration program intended to improve housing quality, with the replacement of mudhouses by brick-houses. It may also have influenced the reduction of household colonization by $T$. infestans and by other household species $[39,40]$.

Despite the success of actions to control triatomines, several other native species were recorded in a larger number of municipalities. They were captured in the household and frequently colonized peridomestic structures. Among them, some were infected and many were being fed by domestic animals and even human blood [41]. In period A, T. sordida was recorded in $26 \%$ of the municipalities, representing $23 \%$ of collected triatomines, while T. pseudomaculata was recorded in $14 \%$ of the municipalities with a relative abundance of $2.5 \%$ of collected triatomines [23]. In period B, T. sordida was recorded in $38 \%$ of municipalities, representing about $82 \%$ of triatomines. T. sordida has been the most common species 
among different regions of the state of Bahia. In a similar situation, T. pseudomaculata was the species that were identified in the largest number of state municipalities in period B $(42 \%)$. The systematic vectorcontrol actions had a very low impact on the spatial distribution of T. sordida and T. pseudomaculata in the state of Bahia. There was a higher occurrence of T. sordida in Western and South Central Bahia, where there are areas of Cerrado, which is the origin biome of this species' natural populations $[1,2,25]$. The highest occurrence of T. pseudomaculata in Western and Central Bahia is in accordance with the occurrence predictions of the species based on environmental variables [42]. The number of specimens of T. sordida and T. pseudomaculata together exceeded $90 \%$ of all triatomines collected in the state between 2006 and 2019.

It was observed a higher occurrence of $T$. brasiliensis and records of similar species in Bahia, expanding observations of Ribeiro-Jr et al. [41]. Before systematized control actions, T. brasiliensis was registered in $6 \%$ of the municipalities of the state of Bahia, and between 2006 and 2019 at least 93 municipalities (22\%) registered this species. In the last few years, other species of the T. brasiliensis complex have been described in the state of Bahia, such as T. juazeirensis, T. melanica, T. sherlocki, and T. petrocchiae [43]. Among these species, we highlight $T$. juazeirensis since it was collected predominantly inside the household units. Other species such as T. tibiamaculata, P. geniculatus, T. melanocephala, and P. Iutzi were detected in the households, mainly the adults.

There was an important difference in the occurrence of $T$. tibiamaculata between the two periods. In period $A$, this species was recorded in about $1 \%$ of the municipalities with a relative abundance of $0.01 \%$ [23] and in period $B$ it was recorded in $4 \%$ of the municipalities with a relative abundance of $0.55 \%$. In recent decades, T. tibiamaculata, which is naturally found in the nests of marsupials, rodents, and epiphytes in forests [1,22], has been recorded in peridomestic palms and inside houses, offering risk of $T$. cruzi transmission in the city of Salvador [44].

The present study has some limitations. The use of reference databases does not allow a broad analysis of the data; it was not possible to obtain data on the occurrence of triatomines within habitats (intra and peridomestic) in period A (1957-1971). Moreover, not all 417 municipalities collect data regularly in period $B$; the health surveillance service classifies municipalities in high, medium and low risk of transmission, emphasizing that there is no obligation to conduct regular entomological research in low-risk municipalities, based on the classification presented by Brazil's Ministry of Health [26]. Future studies reassessing risk classification at a municipal level are urgent for the redefinition of areas and risk of transmission. Further studies should analyze the situation of these silent areas to explain whether the absence of triatomines is due to the functioning of the service or biogeographic issues related to triatomines. In period A, species of $T$. brasiliensis complex were considered as one species - stricto sensu while in period B T. brasiliensis complex was classified into six species: T. brasiliensis, T. juazeirensis, $T$. melanica, T. lenti, T. bahiensis, and T. petrocchiae [43].

This study concludes that there was a change in the occurrence of triatomines between the analyzed periods, 40 years after the implementation of the vector-control program in the state of Bahia. We 
observed a reduction of the occurrence of $P$. megistus and $T$. infestans and an increase of relative abundance and geographic distribution of T. sordida and T. pseudomaculata. Changes in the occurrence of $T$. cruzi main vectors between the studied periods indicate the need for continuity of entomological surveillance actions of Chagas disease. Also, it highlights the importance of promoting and the strengthening of surveillance, community participation, and health education actions of Chagas disease, in addition to new strategies to control triatomines.

\section{Abbreviations}

SESAB: Epidemiologic Surveillance team of Bahia State Health Service; GPS: Global Position System; GIS: Geographic Information System; PAHO/WHO: Pan American Health Organization; DIVEP Epidemiological Surveillance Office; LACEN/BA: Central Public Health Laboratory of Bahia.

\section{Declarations}

\section{Acknowledgements}

We are grateful to the epidemiological surveillance office (SESAB-DIVEP) supported field collection of triatomines and vectors information. The authors are also grateful to Rafaella Albuquerque Silva, Etienne Waleckx and César Augusto Cuba Cuba for suggestions and comments. Also, Natalie Jennifer Hurrell for the help with the English language proofreading.

\section{Ethics approval and consent to participate}

The adopted procedures were in accordance with the ethical standards of the Research Ethics Committee of the Gonçalo Moniz Institute (FIOCRUZ, Bahia, Brazil) $n^{\circ} 2.552 .284$ and with the Helsinki Declaration of 1964 , revised in 1975, 1983, 1989, 1996, and 2000. The consent form was waived because the analysis was based on a state surveillance service of Bahia - Brazil. However, no personal identification data were used to ensure the complete anonymity of participants. The research did not cause any physical, psychic, moral, intellectual, social, cultural, or religious risk to the residents and animals of studied areas. Also, our study did not involve endangered or protected species.

\section{Consent for publication}

Not applicable

\section{Availability of data and materials}

The datasets generated and/or analyzed during the current study are available from the corresponding author on reasonable request. 


\section{Competing interests}

The authors declare that there are no conflicts of interest associated with this study.

\section{Funding}

Fundação de Amparo à Pesquisa do Estado da Bahia (FAPESB) nº 0142013 (PET0023/2013), PROEP/CPqGM process 400904/2013-6, Fiocruz/BA - IGM - scientific initiation scholarship grand. The funding sources of this study had no role in the study design, data collection, data analysis, data interpretation, writing of the report, or in the decision to submit the paper for publication.

\section{Author's Contribution}

GR-Jr, RG-G, and MGR conceived the study. MGR raised funds and administered the project. GR-Jr, RG-G, MGR, contributed to the design of trial methods. CMMC, RFA, FCL, DLPM, GMC, OMFS, CGSS, EOLF, RFS and RBR performed research. GR-Jr and MGR supervised students involved in field and laboratory research. CMMC, RFA, GMC, OMFS, CGSS, RFS obtain the databases, GR-Jr curated the dataset and analyzed the data. GR-Jr, RG-G and MGR drafted the first version of the manuscript. All authors contributed to the interpretation of results, read and commented on manuscript drafts, and approved the final version.

\section{References}

1. Lent $H$, Wygodzinsky P. Revision of the Triatominae (Hemiptera, Reduviidae), and their significance as vectors of Chagas' disease. Bull Am Mus Nat Hist. 1979; 163(3):123-520.

2. Galvao C, Justi SA. An overview on the ecology of Triatominae (Hemiptera:Reduviidae). Acta Trop. 2015; 151:116-125.

3. Barbu CM, Hong A, Manne JM, Small DS, Quintanilla Calderon JE, Sethuraman K et al. The effects of city streets on an urban disease vector. PLoS Comput Biol. 2013; 9(1):e1002801.

4. Waleckx E, Gourbiere S, Dumonteil E. Intrusive versus domiciliated triatomines and the challenge of adapting vector control practices against Chagas disease. Mem Inst Oswaldo Cruz. 2015; 110(3):324-338.

5. Valdez Tah AR, Huicochea Gomez L, Nazar Beutelspacher A, Ortega Canto J, Ramsey JM. Human vulnerability to Trypanosoma cruzi vector transmission through health-disease processes and social appropriation of the territory. Salud Colect. 2015; 11(2):191-210.

6. Gurtler RE, Yadon ZE. Eco-bio-social research on community-based approaches for Chagas disease vector control in Latin America. Trans R Soc Trop Med Hyg. 2015; 109(2):91-98.

7. Rossi JCN, Duarte EC, Gurgel-Gonçalves R. Factors associated with the occurrence of Triatoma sordida (Hemiptera: Reduviidae) in rural localities of Central-West Brazil. Mem Inst Oswaldo Cruz. 2015; 110(2): 192-200. 
8. Forattini OP, Rabello EX, Pattoli DGB, Corrêa RR. Observações sôbre a infestação domiciliar residual por Triatoma infestans. Rev Saúde Públ. 1971; 5(1);17-21.

9. Ribeiro Jr G, Silva-Santos C, Noireau F, Dias-Lima A. Potencial de dispersão de algumas espécies de triatomíneos (Hemiptera: Reduviidae) por aves migratórias. Ser Ci Biol. 2006; 6(4):324-328.

10. Stevens L, Monroy MC, Rodas AG, Dorn PL. Hunting, swimming, and worshiping: human cultural practices illuminate the blood meal sources of cave dwelling Chagas vectors (Triatoma dimidiata) in Guatemala and Belize. PLoS Negl Trop Dis 2014; 8(9):e3047.

11. Silveira AC. Entomological survey (1975-1983). Rev Soc Bras Med Trop. 2011; 44 Suppl 2:26-32.

12. Silveira AC, Dias JC. The control of vectorial transmission. Rev Soc Bras Med Trop. 2011; 44 Suppl 2:52-63.

13. WHO. Control of Chagas Disease. In: WHO Technical Report Series. Edited by Committee RoaWE. Geneva: World Health Organization; 1991; 811.

14. WHO. Chagas disease, Brazil. Wkly Epidemiol Rec. 2000; 75:153-155.

15. Dias JCP, Machado EMM, Fernandes AL, Vinhaes MC. Esboço geral e perspectivas da doença de Chagas no Nordeste do Brasil. Cad. Saúde Públ. 2000; 16(Sup. 2):13-34;

16. Dias JC. Southern Cone Initiative for the elimination of domestic populations of Triatoma infestans and the interruption of transfusional Chagas disease. Historical aspects, present situation, and perspectives. Mem Inst Oswaldo Cruz. 2007; 102 Suppl 1:11-18.

17. Falcão EdC. Pirajá da Silva: o incontestável descobridor do Schistosoma Mansoni / Piraja da Silva: the undisputed finder of Schistosoma Mansoni., vol. 1, 2edn. Brasília: Ministério da saúde; 2008;

18. Brumpt, Silva PD. Existence du Schizotrypanum cruzi Chagas, 1909, à Bahia. (Mata de São João): Biologie du Conorhinus megistus. Bull Soc Pathol Exotique 1912; 5:22-26.

19. Pondé A. A Doença de Chagas na Bahia. Arq Univers Bahia. 1946; 1:333-456.

20. Leal JM, Sherlock IA, Serafim EM. Observações Sobre o Combate aos Triatomíneos Domiciliários com BHC, em Salvador, Bahia. Rev Bras D Trop. 1965; 17(1):65-73.

21. Silva GR. Doença de Chagas em Famílias de Duas Áreas Restritas da Cidade do Salvador, Bahia. Tese. São Paulo: Universidade Federal de São Paulo; 1966;

22. Sherlock IA, Serafim EM. Fauna Triatominae do Estado da Bahia, Brasil. VI - Prevalência Geográfica da Infecção dos Triatomíneos por T. cruzi. Rev Soc Bras Med Trop. 1974; 8(3):129 -141.

23. Sherlock Í, Serafım EM. Fauna Triatominae no Estado da Bahia, Brasil: as espécies e distribuição geográfica. Rev Soc Bras Med Trop 1972; 6 (5): 265-276.

24. Vinhaes MC, de Oliveira SV, Reis PO, de Lacerda Sousa AC, Silva RA, Obara MT, et al. Assessing the vulnerability of Brazilian municipalities to the vectorial transmission of Trypanosoma cruzi using multi-criteria decision analysis. Acta Trop. 2014; 137:105-110.

25. Galvão C. Vetores da doença de Chagas no Brasil. Curitiba, Paraná: Soc Bras Zoo 2014.

26. Sousa OMFd, Santos CGSd, Santos RFd, Fonseca EOL, Lima AGD. Triatomíneos da Bahia: Manual de identificação e orientações para o serviço, vol. 1: Salvador, Bahia: Editora Oxente; 2020. 
27. Silveira A, Feitosa V, Borges R. Distribuição de triatomíneos no ambiente domiciliar, no período de 1975/84, Brasil. Rev Brasil Malariol D Trop. 1984; 36:5-312.

28. Dias JC. Chagas disease: successes and challenges. Cad Saude Publ. 2006; 22(10):2020-2021.

29. Abad-Franch F, Diotaiuti L, Gurgel-Goncalves R, Gurtler RE. Certifying the interruption of Chagas disease transmission by native vectors: cui bono? Mem Inst Oswaldo Cruz. 2013; 108(2):251-254.

30. Censo I. Disponível em:< http://www. censo2010. ibge. gov. br/>. Acesso em 2010;

31. Shaner J, Wrightsell J. Editing in arcMap: Esri; 2000;

32. Malafaia G, de Rodrigues A. Centenário do descobrimento da doença de Chagas: desafios e perspectivas. Rev Soc Bras Med Trop. 2010; 43(5):483-485.

33. Gurgel-Gonçalves R, Galvão C, Mendonça J, Neto E. Guia de triatomíneos da Bahia. Feira de Santana, Bahia: UEFS Editora; 2012.

34. Araujo RF, Jose Mendonca V, Rosa JA, Matos JF, Lima SC, de Araujo Figueiredo MA. Description of a newly discovered Triatoma infestans (Hemiptera: Reduviidae) Foci in Ibipeba, State of Bahia, Brazil. Rev Soc Bras Med Trop. 2014; 47(4):513-516.

35. Brandão H, Fonseca E, Santos R, Júnior G, Santos C, Cova B, et al. Descrição de focos residuais de Triatoma infestans (klug, 1834) no município de Novo Horizonte, Bahia. Rev. Baiana Saúde Públ. 2015; 39:91.

36. de Oliveira AWW, da Silva IG. Geographical distribution and indicators entomologic of sinantropic triatomines captured in the State of Goiás. Rev Soc Bras Med Trop. 2007; 40(2):204-208.

37. Almeida PS, Ceretti Junior W, Obara MT, Santos HR, Barata JM, Faccenda O. Survey of Triatominae (Hemiptera: Reduviidae) fauna in domestic environments and natural infection by

Trypanosomatidae in the State of Mato Grosso do Sul. Rev Soc Bras Med Trop. 2008; 41(4):374-380.

38. Passos AD, Silveira AC. Summary of results from the national surveys. Rev Soc Bras Med Trop. 2011; 44 Suppl 2:47-50.

39. Rodrigues TA, Salvador E. As implicações do Programa de Aceleração do Crescimento (PAC) nas políticas sociais. 2011.

40. dos Santos Pereira A. Uma avaliação do Programa de Aceleração do Crescimento (PAC) no estado da Bahia (2007-10). Rev Adm Públ. 2013; 47(1):177-203.

41. Ribeiro Jr. G, Santos CGS, Lanza F, Reis J, Vaccarezza F, Diniz C, et al. Wide distribution of Trypanosoma cruzi-infected triatomines in the State of Bahia, Brazil. Parasit Vectors. 2019; 12(1):604.

42. Carbajal de la Fuente AL, Porcasi X, Noireau F, Diotaiuti L, Gorla DE. The association between the geographic distribution of Triatoma pseudomaculata and Triatoma wygodzinskyi (Hemiptera:

Reduviidae) with environmental variables recorded by remote sensors. Infect Genet Evol. 2009; Jan;9(1):54-61.

43. Dale C, Almeida CE, Endonça VJ, Oliveira J, da Osa JA, Galvão C, et al. An updated and illustrated dichotomous key for the Chagas disease vectors of Triatoma brasiliensis species complex and their 
epidemiologic importance. Zookeys. 2018.; 805:33-43.

44. Ribeiro Jr G, Gurgel-Goncalves R, Reis RB, Santos CG, Amorim A, Andrade SG, et al. Frequent house invasion of Trypanosoma cruzi-infected triatomines in a suburban area of Brazil. PLoS Negl Trop Dis. 2015; 9(4):e0003678.

\section{Figures}
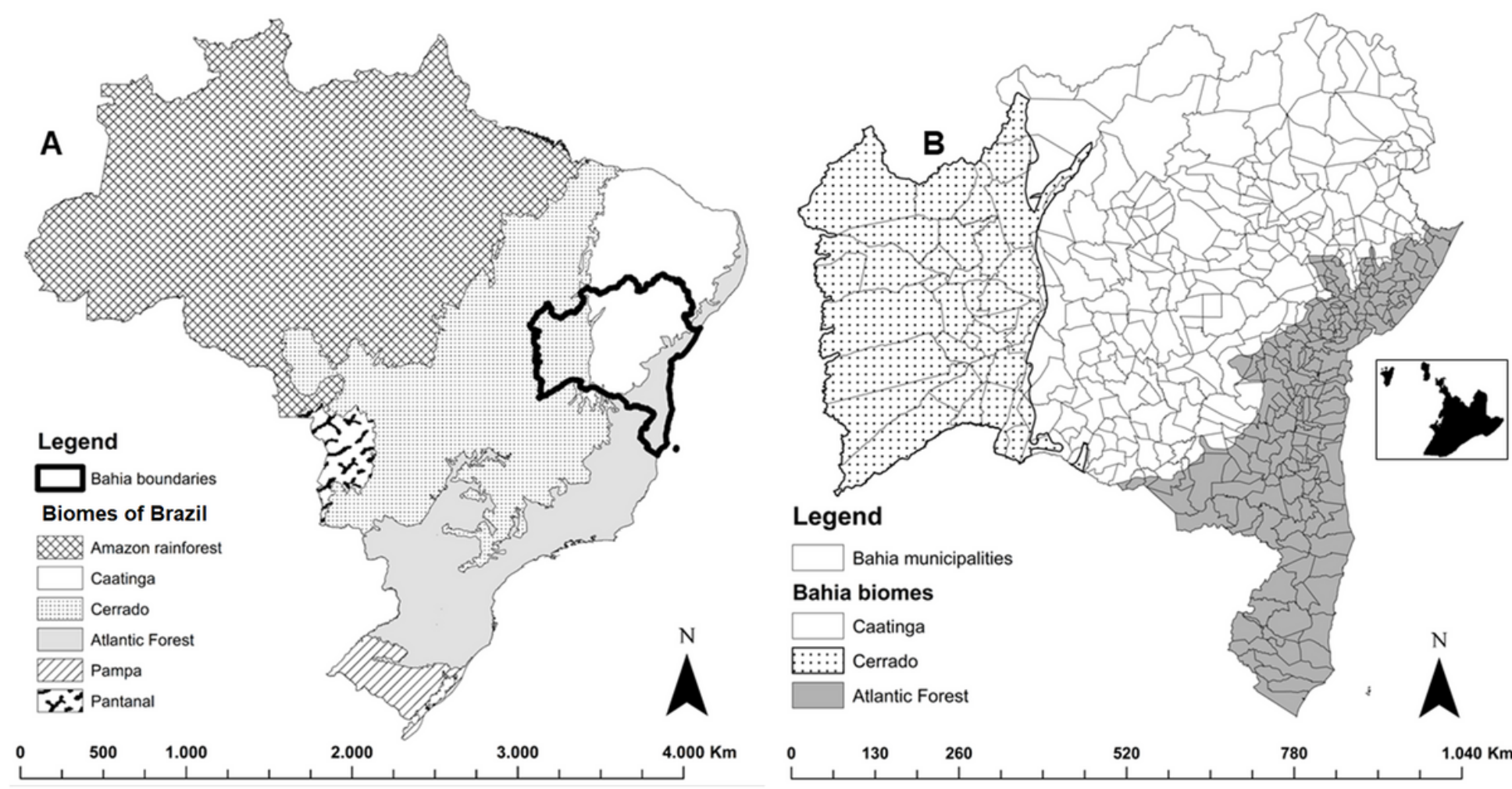

\section{Figure 1}

Study area. Biomes of Brazil and geolocation of Bahia (a). Municipalities of Bahia (b); inset shows the City of Salvador in detail). 


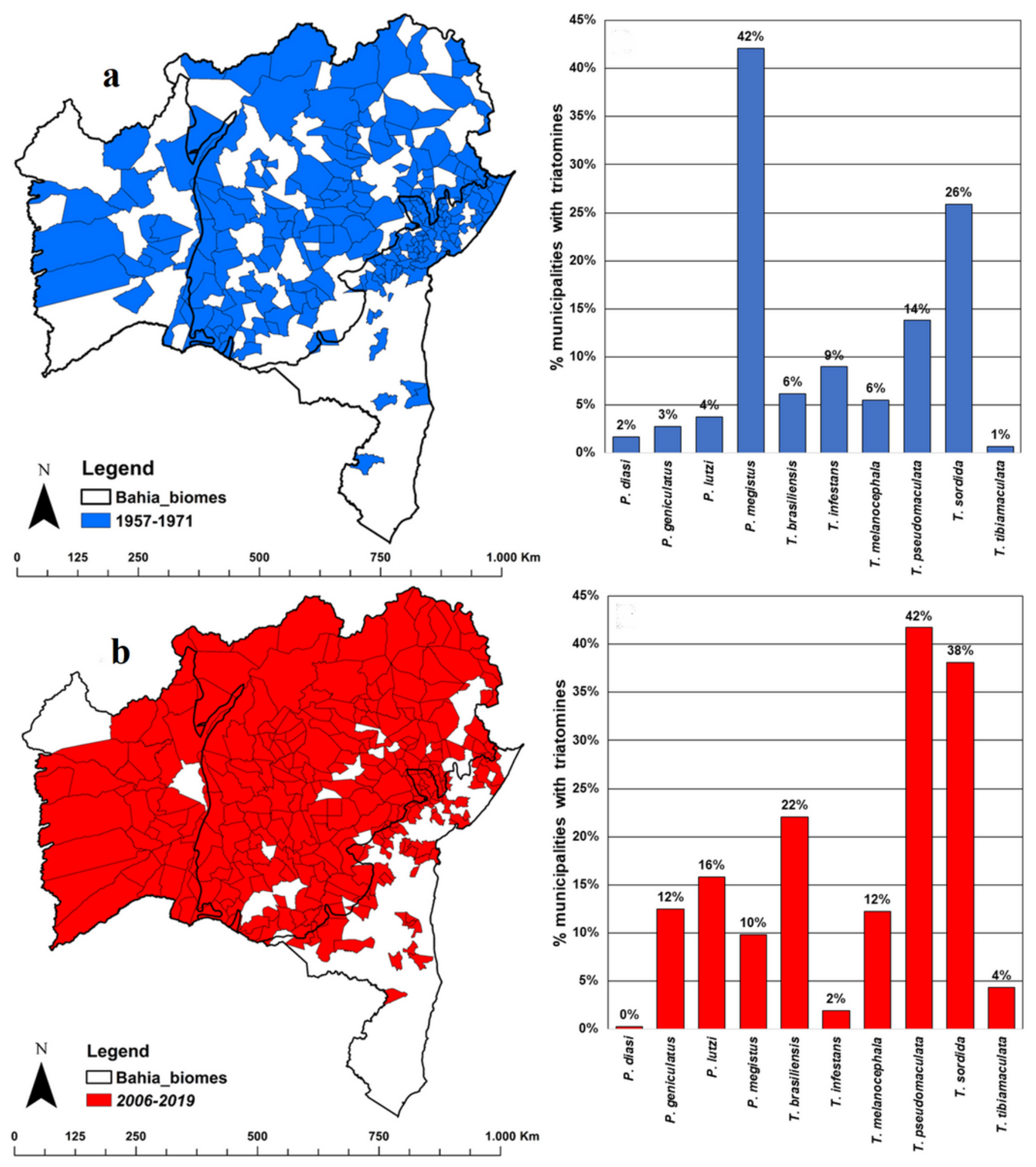

Figure 2

Municipalities with the occurrence of triatomines in the state of Bahia in periods A (1957-1971) and B (2006-2019) and percentage of municipalities with records of the main species of collected synanthropic triatomines. 
Triatoma infestans
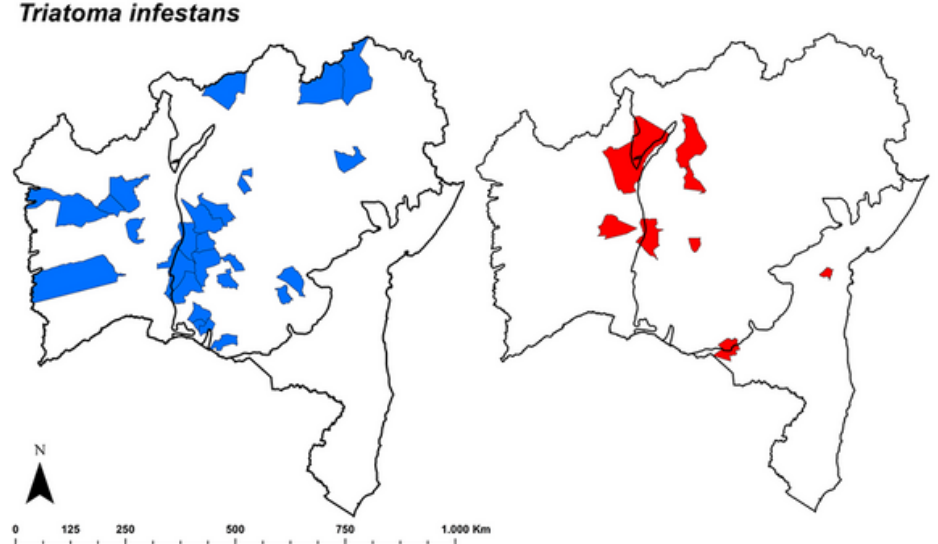

Panstrongylus megistus

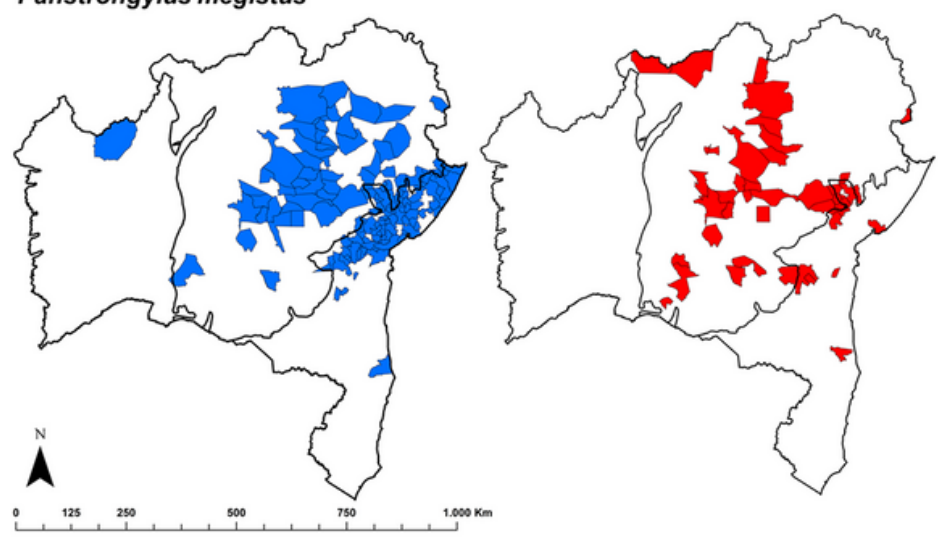

Triatoma sordida
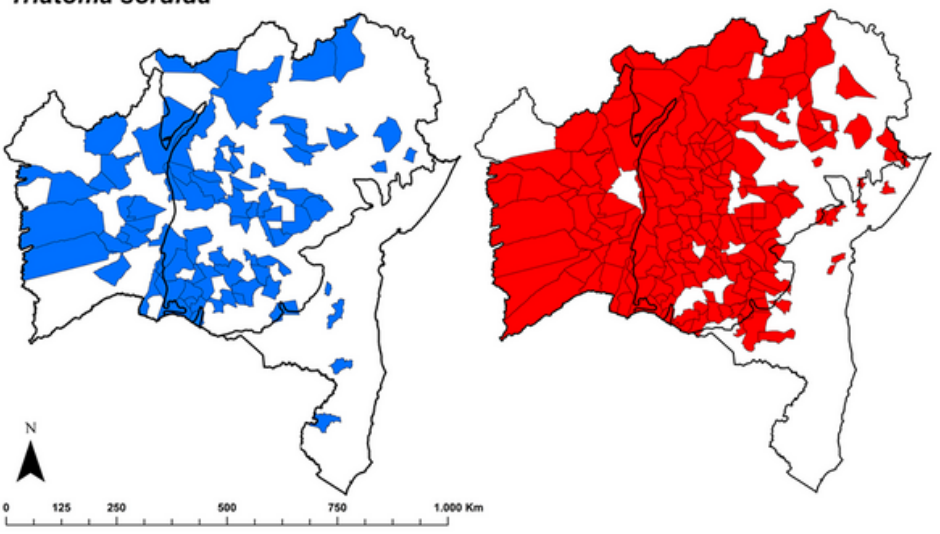

Triatoma pseudomaculata
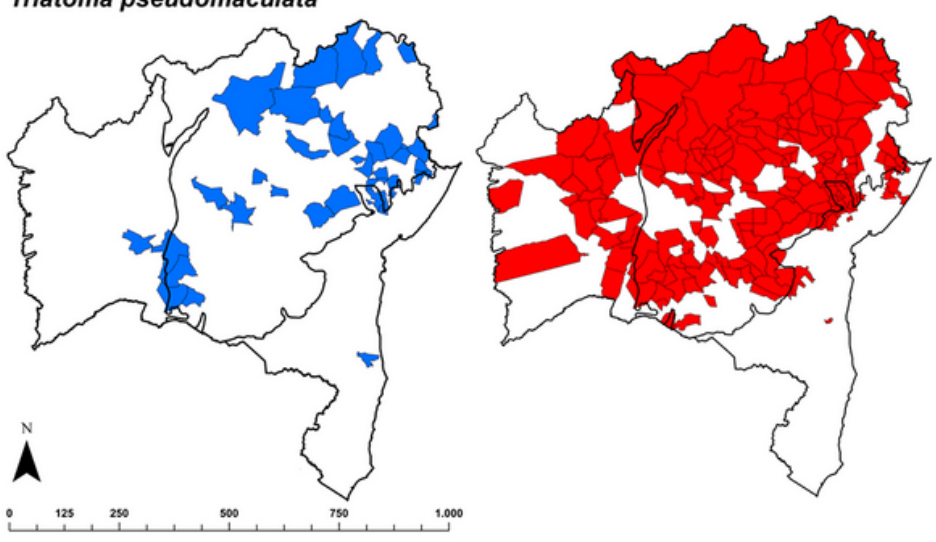

Figure 3

Geographic distribution of Panstrongylus megistus, Triatoma infestans, T. pseudomaculata and T. sordida in the municipalities of the state of Bahia in periods A - in blue (1957-1971) and B - in red (2006-2019).

\section{Supplementary Files}

This is a list of supplementary files associated with this preprint. Click to download.

- MS2Graphicalabstract.jpg 